\title{
Identification of transmission foci of Schistosoma mansoni: narrowing the intervention target from district to transmission focus in Ethiopia
}

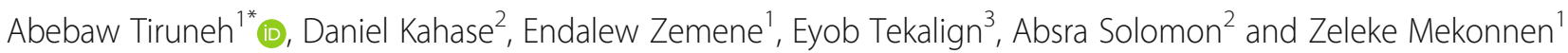

\begin{abstract}
Background: Schistosoma mansoni (S. mansoni) infection is a significant public health problem in Ethiopia, and has wide distribution in the country. The impact of the disease is particularly high on school-age children. Nationwide 385 endemic districts were identified, whereby control and elimination interventions are underway using schoolbased annual mass drug administration (MDA) with praziquantel. The national elimination program targets endemic districts as a whole. The aim of this study was to identify the transmission foci of Schistosoma mansoni and determine prevalence of soil-transmitted helminths (STHs) in Abeshge district.

Methods: The study was conducted from April to May, 2019 among school-age children randomly selected from public elementary schools in Abeshge district, South-central Ethiopia. Demographic information and data on risk factors of S. mansoni infection were gathered using pre-tested questionnaire. Moreover, a stool sample was collected from each child and examined using Kato-Katz thick smear technique. The data were analyzed using STAT A_MP version 12.

Results: A total of 389 school-age children from five public elementary schools were included in the study. The overall prevalence of S. mansoni and STHs was 19.3\% (75/389) and 35\% (136/389), respectively. The prevalence of S. mansoni was $60.6 \%$ in Kulit Elementary school, while it was zero in Geraba. The prevalence of S. mansoni was significantly higher among males ( $A O R=2.6,95 \% \mathrm{Cl} 1.3-5.1$ ), those with habit of swimming and/or bathing in rivers $(A O R=2.9,95 \% \mathrm{Cl} 1.3-5.1)$ and involved in irrigation activities ( $A O R=2.9,95 \% \mathrm{Cl} 1.0-8.3)$. Overall, the prevalence of S. mansoni was significantly higher among school children attending Kulit Elementary School compared to those attending the remaining schools ( $\mathrm{AOR}=12.5,95 \% \mathrm{Cl} 6.2-25.1$ ).

Conclusion: A wide variation of S. mansoni prevalence was observed among the school children in the different schools. Control interventions better identify and target foci of S. mansoni transmission, instead of targeting the district homogenously.
\end{abstract}

Keywords: Schistosoma mansoni, School-age children, Transmission foci, Ethiopia

\footnotetext{
* Correspondence: abebawtiruneh@gmail.com

'School of Medical Laboratory Sciences, Institute of Health, Jimma University, Jimma, Ethiopia

Full list of author information is available at the end of the article
}

(c) The Author(s). 2020 Open Access This article is licensed under a Creative Commons Attribution 4.0 International License, which permits use, sharing, adaptation, distribution and reproduction in any medium or format, as long as you give appropriate credit to the original author(s) and the source, provide a link to the Creative Commons licence, and indicate if changes were made. The images or other third party material in this article are included in the article's Creative Commons licence, unless indicated otherwise in a credit line to the material. If material is not included in the article's Creative Commons licence and your intended use is not permitted by statutory regulation or exceeds the permitted use, you will need to obtain permission directly from the copyright holder. To view a copy of this licence, visit http://creativecommons.org/licenses/by/4.0/. The Creative Commons Public Domain Dedication waiver (http://creativecommons.org/publicdomain/zero/1.0/) applies to the data made available in this article, unless otherwise stated in a credit line to the data. 


\section{Background}

Schistosomiasis (bilharzia) is a parasitic disease caused by blood flukes (trematodes) of the genus Schistosoma. Five species of Schistosoma, Schistosoma mansoni (S. mansoni), Schistosoma japonicum (S. japonicum), Schistosoma intercalatum (S. intercalatum), Schistosoma mekongi (S. mekongi) and Schistosoma haematobium (S. haematobium) are known to cause human schistosomiasis. The intermediate hosts for the two major species, $S$. mansoni and S. haematobium, are snails of the genus Biomphalaria and Bulinus, respectively. The snails inhabit fresh water bodies. The disease is endemic in 78 countries with an estimated 779 million people at-risk and about 190 million people already infected in 2016 $[1,2]$. About $90 \%$ of the global burden of schistosomiasis occurs in Africa, and is caused by S. mansoni (intestinal schistosomiasis) and S. haematobium (urogenital schistosomiasis) in the continent [1,3]. The disease burden is high in sub-Saharan Africa where environmental and host (human) factors favor the transmission and growth of the parasites and their intermediate hosts $[4,5]$. The transmission of Schistosoma is highly focal; restricted to environments with fresh water bodies infested by appropriate snail intermediate hosts, and where open field defecation and human-water contact is common $[6,7]$.

The most vulnerable groups to acquire Schistosoma infections are school-aged children (SAC) and at-risk adults (pregnant, lactating women and individuals who frequently contact infested fresh water bodies due to their occupation). School-aged children in developing countries are particularly affected by the disease [8]. The administration of preventive chemotherapy during control programs mainly targets this age group. Specific area or localities of the community may fall at different transmission risk levels based on the prevalence of schistosomiasis among SAC $[9,10]$. Accordingly, a community may be classified as high risk community (> $50 \%$ prevalence), moderate risk community (20-50\% prevalence) and low risk community ( $<20 \%$ prevalence). Based on these categories, mass drug administration (MDA) with praziquantel is recommended to SAC and the whole community once a year in high-risk communities, SAC and at-risk community groups once every 2 years in moderate-risk communities and only SAC twice during their primary schooling in low-risk communities [11, 12].

Ethiopia is among schistosomiasis high-burden countries with estimated 38.3 million people at risk of acquiring the infection and 5.01 million already infected in 2012. The predominant Schistosoma species in the country is $S$. mansoni, while $S$. haematobium is mainly limited to areas adjacent to the Awash River Valley [13, 14]. The disease causes devastating health problems including nutritional, cognitive and pathological effects among infected individuals. School-age children particularly suffer growth retardation, low school performance, cognitive impairments, anemia, nutritional disorders and remarkable pathological illness from egg granuloma [10, 15-18]. Considering this, MDA with praziquantel was underway in endemic districts of the country targeting SAC since the last decade [19].

Mapping of schistosomiasis and other Neglected Tropical Diseases (NTDs) at national level was completed recently. The mapping identified 385 endemic districts requiring $\mathrm{MDA}$, and about 5 million SAC were treated with praziquantel in 2015 alone. It is also planned to scale up the MDA coverage from SAC to include at-risk adults for the achievement of the national goal of schistosomiasis control and elimination by 2020 and 2025, respectively [12, 20]. Although substantial successes were recorded in minimizing the disease burden and egg intensity among treated SAC [13,21], the overall coverage of praziquantel treatment was low (36\%) in 2016 [12]. The control program also faced several challenges including incomplete mapping, re-infection, program reliance on MDA and targeting of SAC only [9, 22]. Some of these challenges may partly be due to the classification of $S$. mansoni transmission areas at district level while the transmission is highly focal depending on the existence of fresh water bodies and appropriate snail intermediate hosts. For instance, in a study conducted in Chilga district, Northwest Ethiopia, a wide variation in infection range from zero prevalence in some schools to high burden of infection in other schools was reported [23]. Being in the same district, the MDA is administered in kebeles (smallest administrative units/localities in Ethiopia) with no S. mansoni transmission, which poses several challenges. This necessitates identifying and targeting at-risk areas where active transmission of S. mansoni occur. The aim of this study was to identify the transmission foci of $S$. mansoni and determine prevalence of STHs in Abeshge district.

\section{Methods}

\section{Study design and setting}

A cross-sectional study was conducted from April to May, 2019 in randomly selected public elementary SAC in Abeshge district. The district is located in Gurage zone, $155 \mathrm{kms}$ south of Addis Ababa. The weather is warm, and there are rivers in some of the kebeles. Smallscale irrigation is practiced in some kebeles, which may create favorable conditions for $S$. mansoni transmission. Abeshge district has 25 administrative kebeles, with one public elementary school located in each kebele. In 2018, the estimated total population of the district was 81,119 . 


\section{Sample size and sampling technique}

The sample size was calculated as 400 using single population proportion formula, assuming proportion of infection among the children to be 0.13 [24], at 95 confidence level and margin of error of 0.05, design effect of 2 and 15\% non-response rate.

First, five elementary schools were randomly selected from the total of 25 primary schools located in the district. The selected schools were Geraba, Kulit, Jeju, Walga and Hole elementary schools and the total number of SAC in each school was 651, 595, 643, 635 and 691, respectively. The total sample size was allocated to the selected schools proportional to the total number of the SAC in each school. Systematic random sampling technique was used to select the study participants from each class room using class rosters as sampling frame. Accordingly, 80, 86, 74, 79 and 81 SAC were selected from Jeju, Hole, Kulit, Walga and Geraba Elementary Schools, respectively. School children who were treated with anti-helminthic drugs in the last 2 weeks prior to the survey and those who could not provide stool samples after two visits were excluded from the study. Few of the SAC were 15 years of age, likely due to late school enrolment.

\section{Data collection}

Semi-structured questionnaire was used to collect data on socio-demographic and associated risk factors of schistosomiasis among the SAC. The questionnaire was first developed in English and translated to Amharic (Additional file 1). Three trained laboratory personnel interviewed parents/guardians of the children after obtaining written consent. Moreover, thumb-sized stool sample was collected from each child using clean leak-proof stool cups. School-aged children who could not provide stool sample on the first visit were instructed to provide on the following day. The collected stool samples were transported to Wolkite University Microbiology and Parasitology Laboratory using cold box. Kato-Katz thick smear technique was employed for the detection and quantification of S. mansoni and STH eggs, following standard operating procedures. A single specimen of each child and single Kato-Katz smear of each specimen was processed.

\section{Data analysis}

Egg per gram (EPG) of $S$. mansoni was obtained by multiplying the number of eggs counted in $41.7 \mathrm{mg}$ of the Kato-Katz template by the factor 24. [25]. The infection intensity was classified as light (1-99 EPG), moderate (100-399 EPG) and heavy (> 400 EPG) infection [11]. The data were entered into Microsoft Excel and cleaned. The data were analyzed using STATA_MP version 12 (Stata Corp., TX, USA). Descriptive statistics including frequency, percentage and mean were computed to summarize socio-demographic characteristics of the SAC. Bivariate analysis of each independent variable with the dependent variable was performed. Variables with $p$ value less than 0.2 during bivariate analysis were candidates for the multivariable analysis. Odds ratios and the corresponding 95\% confidence intervals were calculated to measure the strength of association. Statistical significance was set at $p$ value less than 0.05 .

\section{Results}

Demographic characteristics of the study participants A total of 389 SAC were enrolled in this study with response rate of $97 \%$. Out of the total study participants, $199(51.2 \%)$ were males and $218(56 \%)$ were in the age group of 5-10 years. Thirty-eight (9.8\%) of the study participants were from households lacking their own latrine, and about half (50.4\%) practiced open field defecation. Majority of family members of the study participants $(91.3 \%)$ obtain drinking water from protected sources (Table 1).

\section{Prevalence of Schistosoma mansoni and STHs}

The overall prevalence of S. mansoni and STHs was $19.3 \%(75 / 389)$ and 35\% (136/389), respectively. Other intestinal parasites including Enterobius vermicularis ( $E$. vermicularis), Hymenolepis nana (H. nana) and Taenia species were detected in less than $5 \%$ of the study

Table 1 Socio-demographic characteristics of the study participants, Abeshge district, South-central Ethiopia

\begin{tabular}{lll}
\hline Characteristics & & Frequency n(\%) \\
\hline Age group & $5-10$ & $218(56.0)$ \\
Sex & $11-15$ & $171(44.0)$ \\
& Male & $199(51.2)$ \\
Grade & Female & $190(48.8)$ \\
& $1-4$ & $297(76.3)$ \\
Family size & $5-8$ & $92(23.7)$ \\
& $\leq 5$ & $121(31.1)$ \\
Occupation of household head & Farmer & $268(68.9)$ \\
& Merchant & $65(76.7)$ \\
& Daily laborer & $22(5.7)$ \\
& Employed & $27(6.9)$ \\
Latrine availability & No & $38(9.8)$ \\
Latrine use & Yes & $351(90.2)$ \\
& Sometimes & $196(50.4)$ \\
Drinking water source & Always & $193(49.6)$ \\
& Protected & $355(91.3)$ \\
& Unprotected & $34(8.7)$ \\
\hline
\end{tabular}


participants. All the STH infections were due to the hookworms (except a single case of Trichuris trichiura). The geometric mean egg count of $S$. mansoni was 191.3 EPG. Light, moderate and heavy infections of S. mansoni were 28(37.3\%), 26(34.7\%) and 21(28\%), respectively. None of the SAC from Geraba Elementary School were positive for S. mansoni, whereas $60.6 \%(43 / 71)$ of the children from Kulit Elementary School were S. mansoni infected (Table 2).

\section{Risk factors associated with Schistosoma mansoni infection}

Out of the total study participants, 205(52.7\%) had the habit of swimming and/or bathing in rivers. The prevalence of S. mansoni among SAC who had the habit of swimming and/or bathing in rivers was 29.8\% (61/205). School-age children who responded participation in irrigation activities were 28(7.2\%), half of whom were positive for $S$. mansoni. Although latrine coverage among households of the study participants was $90.2 \%$, open field defecation habit was reported by $50.4 \%$ of the SAC. Using bivariate analysis (Table 3$)$, sex $(\mathrm{COR}=2.6,95 \% \mathrm{CI}$ 1.5-4.4), habit of swimming and/or bathing in rivers $(\mathrm{COR}=1.9,95 \% \mathrm{CI} 1.1-3.3)$, participation in irrigation activities (COR $=4.9,95 \% \mathrm{CI} 2.2-10.8)$ and residence/ school $(\mathrm{COR}=13.7$, 95\%CI 7.5-25.0) were significantly associated with $S$. mansoni infection.

Predictors of $S$. mansoni infection are presented in Table 4. Accordingly, after adjusting for other variables, there were significant differences in prevalence of $S$. mansoni by sex $(\mathrm{AOR}=2.6,95 \% \mathrm{CI} 1.3-5.1)$, the habit of swimming and/or bathing in rivers $(\mathrm{AOR}=2.9,95 \% \mathrm{CI}$ 1.3-5.1), involvement in irrigation $(\mathrm{AOR}=2.9,95 \% \mathrm{CI}$ 1.0-8.3) and attending Kulit Elementary School (AOR = 12.5, 95\%CI 6.2-25.1).

\section{Discussion}

This study aimed at identifying transmission foci of $S$. mansoni by determining its prevalence among SAC in the district. Overall, nearly a fifth of the SAC had S. mansoni infection and more than a third of the children had STH

Table 2 Prevalence of Schistosoma mansoni among each elementary school children, Abeshge district, South-central Ethiopia

\begin{tabular}{|c|c|c|c|}
\hline \multirow{2}{*}{$\begin{array}{l}\text { Name of } \\
\text { the } \\
\text { Elementary } \\
\text { School }\end{array}$} & \multirow{2}{*}{$\begin{array}{l}\text { \# } \\
\text { examined } \\
(\%)\end{array}$} & \multicolumn{2}{|c|}{ Schistosoma mansoni infection } \\
\hline & & Positive $n(\%)$ & Negative $\mathrm{n}(\%)$ \\
\hline Jeju & $80(20.6)$ & $7(8.8)$ & $73(91.2)$ \\
\hline Hole & $86(22.1)$ & $10(11.6)$ & $76(88.4)$ \\
\hline Kulit & $71(18.3)$ & $43(60.6)$ & $28(39.4)$ \\
\hline Walga & $76(19.5)$ & $16(21.1)$ & $60(78.9)$ \\
\hline Geraba & 76 (19.5) & $0(0)$ & 76 (100) \\
\hline
\end{tabular}

infections. Almost all the STH infections were caused by hookworms. Hookworm infections may result in iron deficiency anemia, adversely affecting school performance of the children [26]. The prevalence of both S. mansoni and STHs was higher compared to the earlier report from the same district [24]. The difference could be due to wide variation in prevalence of $S$. mansoni infection in the different sampled kebeles. In spite of school MDA interventions [19], transmission of the disease is ongoing. Depending on how long the children were infected, the children may experience clinical manifestations including acute Katayama fever and chronic egg granuloma which may result in portal hypertension and gastro-intestinal bleeding [27]. This may lead to malnutrition and ill health with subsequent impact on school performance and absenteeism $[17,18,28,29]$. The disease may also adversely affect productivity of adults in the district as the disability adjusted life years (DALYs) due to schistosomiasis is high in Africa [10, 30].

Human infection with $S$. mansoni occurs by skin penetration with cercaria in fresh water bodies. In this study, children who reported to swim and/or bath in rivers were three times more likely to be infected with $S$. mansoni as compared to those who did not have the habit. Studies conducted elsewhere also revealed significant association of contact with fresh water bodies and S. mansoni infection [31-33]. On the other hand, half of the study participants practice open field defecation which may result in fecal contamination of water bodies in the area. The prevalence of $S$. mansoni was relatively higher in Kulit and Walga kebeles. The presence of rivers crossing these areas may favor transmission of S. mansoni in those kebeles. Moreover, small-scale irrigation is common in these kebeles. Children who reported participation in irrigation activities had significantly higher prevalence of $S$. mansoni infection compared to those who did not participate in irrigation. The construction of hydro-electric dams and irrigation projects in Ethiopia may create favorable habitat for snail intermediate hosts [34]. For instance, the incidence of S. mansoni was increased following the construction of irrigation microdams in Tigray region, Northern Ethiopia [35]. The abundance of Biomphalaria pfeifferi also ascend from the source river to secondary (line from river) and tertiary (line to/in the farm) irrigation canals [36] which may increase the likelihood of cercaria skin penetration during irrigation activities. Other studies also reported the risk of irrigation to $S$. mansoni infection among children and adults [31, 37].

In this study, S. mansoni infection was significantly associated with sex of the children, with males more than twice likely to be infected compared to females. This could be attributed to difference in behavior of males compared to the females. Males often play outdoors and 
Table 3 Bivariate analysis of factors associated with Schistosoma mansoni infection, Abeshge district, South-central Ethiopia

\begin{tabular}{|c|c|c|c|c|c|}
\hline Variables & & Examined $n(\%)$ & Positive n(\%) & COR $(95 \% \mathrm{Cl})$ & $\boldsymbol{p}$-value \\
\hline \multirow[t]{2}{*}{ Age group } & $5-10$ & $218(56.0)$ & $39(17.9)$ & Ref & Ref \\
\hline & $11-15$ & $171(44.0)$ & $36(21.1)$ & $1.2(0.7-2.0)$ & 0.433 \\
\hline \multirow[t]{2}{*}{ Sex } & Male & $199(51.2)$ & $52(26.1)$ & $2.6(1.5-4.4)^{*}$ & 0.001 \\
\hline & Female & $190(48.8)$ & $23(12.1)$ & Ref & Ref \\
\hline \multirow[t]{2}{*}{ Grade } & $1-4$ & $297(76.3)$ & $62(20.9)$ & $1.6(0.8-3.1)$ & 0.155 \\
\hline & $5-8$ & $92(23.7)$ & $13(14.1)$ & Ref & Ref \\
\hline \multirow[t]{2}{*}{ Family size } & $\leq 5$ & $121(31.1)$ & $26(21.5)$ & $1.2(0.7-2.1)$ & 0.459 \\
\hline & $>5$ & $268(68.9)$ & 49 (18.3) & Ref & Ref \\
\hline \multirow[t]{4}{*}{ Household head occupation } & Merchant & $65(16.7)$ & $10(15.4)$ & Ref & Ref \\
\hline & Farmer & $275(70.7)$ & $54(19.6)$ & $1.3(0.6-2.8)$ & 0.432 \\
\hline & Daily laborer & $22(5.7)$ & $6(27.3)$ & $2.1(0.6-6.5)$ & 0.219 \\
\hline & Employed & $27(6.9)$ & $5(18.5)$ & $1.3(0.4-4.1)$ & 0.711 \\
\hline \multirow[t]{2}{*}{ Latrine availability } & No & $38(9.8)$ & $8(21.1)$ & $1.1(0.5-2.6)$ & 0.771 \\
\hline & Yes & $351(90.2)$ & $67(19.1)$ & Ref & Ref \\
\hline \multirow[t]{2}{*}{ Latrine use } & Sometimes & $196(50.4)$ & $38(19.4)$ & $1.0(0.6-1.7)$ & 0.957 \\
\hline & Always & $193(49.6)$ & $37(19.2)$ & Ref & Ref \\
\hline \multirow[t]{2}{*}{ Drinking water source } & Protected & $355(91.3)$ & $68(19.2)$ & Ref & Ref \\
\hline & Unprotected & $34(8.7)$ & $7(20.6)$ & $1.1(0.5-2.6)$ & 0.840 \\
\hline \multirow[t]{2}{*}{ Swimming and/or bath in rivers } & No & $184(47.3)$ & $14(7.6)$ & Ref & Ref \\
\hline & Yes & $205(52.7)$ & $61(29.8)$ & $5.1(2.8-9.6)^{*}$ & 0.001 \\
\hline \multirow[t]{2}{*}{ Washing cloth in rivers } & No & $107(27.5)$ & $18(16.8)$ & Ref & Ref \\
\hline & Yes & $282(72.5)$ & $57(20.2)$ & $1.3(0.7-2.2)$ & 0.450 \\
\hline \multirow[t]{2}{*}{ Participation in irrigation } & No & $361(92.8)$ & $61(16.9)$ & Ref & Ref \\
\hline & Yes & $28(7.2)$ & $14(50.0)$ & $4.9(2.2-10.8)^{*}$ & 0.001 \\
\hline \multirow[t]{2}{*}{ School } & Kulit & $71(18.3)$ & $43(60.6)$ & $13.7(7.5-25.0)^{*}$ & 0.001 \\
\hline & Others & $318(81.7)$ & $32(10.1)$ & Ref & Ref \\
\hline
\end{tabular}

Ref Reference * Statistically significant at $p<0.05$

the frequency of contact with river water is likely higher. In terms of social-cultural context, males have freedom to swim and bath in rivers compared to the females, thereby predisposing the males to higher risk of $S$. mansoni infection [38, 39]. Similarly, studies done in Ejaji [40] and Wolaita [41] also reported significantly higher prevalence of $S$. mansoni infection among male children compared to females.

Parasitic infections often have focal distribution, depending on several environmental and social factors. In this study, SAC from Kulit had significantly higher prevalence of $S$. mansoni infection compared to the other schools. This is likely due to presence of river crossing the kebele and presence of small-scale irrigation. Considering prevalence heterogeneity among kebeles within the same district is important during schistosomiasis control and elimination interventions. The Ethiopian NTDs master plan classified 48.6\% (385/ $793), 44.8 \%$ (355/793) and 6.7\% (53/793) of the districts of the country as Schistosoma-endemic, Schistosoma-free and districts with unknown prevalence, respectively. The Schistosoma-endemic districts require preventive chemotherapy [20]. However, due to the high focal transmission nature of the disease [7], classification of transmission intensity at district level may result in unnecessary treatment of Schistosoma-free kebeles in endemic districts. S. mansoni control and elimination interventions should be based on fine-scale mapping within districts [42]. In this study, the prevalence of $S$. mansoni ranged from zero (Geraba elementary school) to $60.6 \%$ (Kulit elementary school), which indicates a wide variation in transmission intensity within the same district. The annual MDA given for the SAC is also similar between low to high prevalence kebeles. Earlier study conducted among SAC in Chilga district, Northwest Ethiopia also documented three out of seven elementary schools had zero prevalence of S. mansoni [23]. This calls for locality-specific intervention program in the same district by considering transmission intensity/ prevalence variations. The national health system and 
Table 4 Multivariable analyses of risk factors of Schistosoma mansoni infection, Abeshge district, South-central Ethiopia

\begin{tabular}{|c|c|c|c|c|c|}
\hline Characteristics & & Examined $n(\%)$ & Positive (\%) & $\mathrm{AOR}(95 \% \mathrm{Cl})$ & $p$-value \\
\hline \multirow[t]{2}{*}{ Age group } & $5-10$ & $218(56.0)$ & $39(17.9)$ & Ref & Ref \\
\hline & $11-15$ & $171(44.0)$ & $36(21.1)$ & $1.3(0.6-2.6)$ & 0.542 \\
\hline \multirow[t]{2}{*}{ Sex } & Male & $199(51.2)$ & $52(26.1)$ & $2.6(1.3-5.1)$ & $0.001^{*}$ \\
\hline & Female & $190(48.8)$ & $23(12.1)$ & Ref & Ref \\
\hline \multirow[t]{2}{*}{ Grade } & $1-4$ & $297(76.3)$ & $62(20.9)$ & $1.7(0.7-4.1)$ & 0.267 \\
\hline & $5-8$ & $92(23.7)$ & $13(14.1)$ & Ref & Ref \\
\hline \multirow[t]{4}{*}{ Household head occupation } & Merchant & $65(16.7)$ & $10(15.4)$ & Ref & Ref \\
\hline & Farmer & $275(70.7)$ & $54(19.6)$ & $1.7(0.7-4.2)$ & 0.233 \\
\hline & Daily laborer & $22(5.7)$ & $6(27.3)$ & $3.5(0.9-14.0)$ & 0.075 \\
\hline & Employed & $27(6.9)$ & $5(18.5)$ & $0.9(0.2-4.1)$ & 0.927 \\
\hline \multirow[t]{2}{*}{ Water source } & Protected & $355(91.3)$ & $68(19.2)$ & ref & Ref \\
\hline & Unprotected & $34(8.7)$ & 7 (20.6) & $0.9(0.3-2.6)$ & 0.829 \\
\hline \multirow[t]{2}{*}{ Swimming and/or bath in rivers } & No & $184(47.3)$ & $14(7.6)$ & Ref & Ref \\
\hline & Yes & $205(52.7)$ & $61(29.8)$ & $2.9(1.3-5.1)$ & $0.004^{*}$ \\
\hline \multirow[t]{2}{*}{ Washing clothes in river } & No & $107(27.5)$ & $18(16.8)$ & Ref & Ref \\
\hline & Yes & $282(72.5)$ & $57(20.2)$ & $1.2(0.6-2.3)$ & 0.653 \\
\hline \multirow[t]{2}{*}{ Participate in irrigation activities } & No & $361(92.8)$ & $61(16.9)$ & Ref & Ref \\
\hline & Yes & $28(7.2)$ & $14(50.0)$ & $2.9(1.0-8.3)$ & $0.046^{*}$ \\
\hline \multirow[t]{2}{*}{ Schools } & Kulit & $71(18.3)$ & $43(60.6)$ & $12.5(6.2-25.1)$ & $0.001^{*}$ \\
\hline & Others & $318(81.7)$ & $32(10.1)$ & Ref & Ref \\
\hline
\end{tabular}

health sector transformation plan also support districtbased disease assessment and control interventions to assess disease profile of each kebele [43].

Narrowing the target area from district to transmission foci will also help in resolving challenges of the current national program including coverage query, its dependence on school-based MDA, and high re-infection rate of S. mansoni particularly in high transmission settings [7, 9, 22]. The coverage of MDA among SAC in Ethiopia is still less than half of the plan and about 53 districts lack baseline prevalence to classify the level of endemicity of schistosomiasis $[9,20]$. It also appears that less emphasis is given to snail control and environmental management at national level. However, interventions targeting the snail intermediate hosts remarkably help in the control and elimination of the disease [44]. Providing annual MDA for SAC in Ethiopia may not address other age groups and SAC who are out of school. The burden of S. mansoni in this study may also indicate high burden of schistosomiasis among their family members [45]. This may sustain the transmission by provoking environmental fecal contamination and fuel re-infection rate after MDA.

In this study, the single stool specimen of each child and single Kato-Katz smear of each specimen processed might have underestimated the prevalence. Moreover, identification of the transmission foci and burden of infection in this study involved only stool examination with no malacological component, which could provide additional information on the transmission [46-48].

\section{Conclusion}

A wide variation in the prevalence of S. mansoni was observed among the different schools. S. mansoni infection was significantly higher among males, children who had habit of swimming and/or bathing and in those participating in irrigation activities. Therefore, health information on the risk factors and prevention methods of schistosomiasis need to be provided for the SAC. Schistosomiasis control and elimination interventions better identify and target foci of S. mansoni transmission instead of targeting the district homogenously.

\section{Supplementary information}

Supplementary information accompanies this paper at https://doi.org/10. 1186/s12889-020-08904-1.

Additional file 1 (A) Questionnaire developed for the assessment of socio-demographic characteristics of the school children. (B) Questionnaire developed to assess risk factors of S. mansoni infection among the school children

\section{Abbreviations}

DALYs: Disability-adjusted life years; EPG: Eggs per gram; MDA: Mass drug administration; NTDs: Neglected tropical diseases; SAC: School-age children; STHs: Soil-transmitted helminths; WHO: World health organization 


\section{Acknowledgements}

We thank Wolkite University for funding the study, and Abeshge District Health Office and Education Office for facilitating the field work. We are grateful to the children and their parents for consenting to take part in the study.

\section{Authors' contributions}

AT and DK conceived the study. AT, DK, ET and AS were involved in the designing of the research and data collection acquisition. AT and EZ involved in data analysis and drafted the manuscript. ZM critically reviewed the manuscript. All authors read and approved the final version of the manuscript.

\section{Funding}

The research was funded by Wolkite University. The funder had no role in the design of the study, collection, analysis and interpretation of data, and manuscript preparation.

\section{Availability of data and materials}

All materials and data are available in the hands of corresponding author if requested.

\section{Ethics approval and consent to participate}

Ethical clearance was obtained from Ethical Review Board of Wolkite University (Ref.No 139/11). Support letter was obtained from Abeshge District Health and Education Offices to each primary school. After explaining aims of the study, written informed consent was obtained from the parents/ guardians of the children. Confidentiality of the data was maintained at all levels. School children who were positive for S. mansoni and STHs were treated following national guidelines at the nearby health centers.

\section{Consent for publication}

Not applicable.

\section{Competing interests}

We declare that we do not have competing interests.

\section{Author details}

${ }^{1}$ School of Medical Laboratory Sciences, Institute of Health, Jimma University, Jimma, Ethiopia. ${ }^{2}$ Department of Medical Laboratory Sciences, College of Medicine and Health Sciences, Wolkite University, Wolkite, Ethiopia. ${ }^{3}$ Department of Medical Laboratory Sciences, College of Health Sciences, Mizan-Tepi University, Mizan-Tepi, Ethiopia.

Received: 28 January 2020 Accepted: 12 May 2020

Published online: 24 May 2020

\section{References}

1. World Health Organization. Integrating neglected tropical diseases in global health and development. Fourth WHO report on neglected tropical diseases. Geneva: WHO; 2017.

2. GBD 2016 Disease and Injury Incidence and Prevalence Collaborators. Global, regional, and national incidence, prevalence, and years lived with disability for 328 diseases and injuries for 195 countries, 1990-2016: a systematic analysis for the Global Burden of Disease Study 2016. Lancet (London, England). 2017;390(10100):1211-59.

3. Mitra AK, Mawson AR. Neglected tropical diseases: epidemiology and global burden. Trop Med Infect Dis. 2017;2:36.

4. Adekiya TA, Aruleba RT, Oyinloye BE, Okosun KO, Kappo AP. The effect of climate change and the snail-Schistosome cycle in transmission and biocontrol of Schistosomiasis in sub-Saharan Africa. Int J Environ Res Public Health. 2019;17:181.

5. Brooker S. Spatial epidemiology of human schistosomiasis in Africa: risk models, transmission dynamics and control. Trans R Soc Trop Med Hyg. 2007;101:1-8.

6. Tchuenté LT, Rollinson D, Stothard JR, Molyneux D. Moving from control to elimination of schistosomiasis in sub-Saharan Africa : time to change and adapt strategies. Infect Dis Poverty. 2017;6:42.

7. Ciddio M, Mari L, Sokolow SH, De Leo GA, Casagrandi R, Gatto M. Advances in water resources the spatial spread of schistosomiasis : a multidimensional network model applied to Saint-Louis region, Senigal. Adv Water Resour. 2017;108:406-15.

8. Inobaya MT, Olveda RM, Chau TN, Olveda DU, Ross AG. Prevention and control of schistosomiasis: a current perspective. Res Rep Trop Med. 2014; 2014:65-75

9. Negussu N, Mengistu B, Kebede B, Deribe K, Ejigu E, Tadesse G, et al. Ethiopia Schistosomiasis and soil-transmitted helminthes control Programme : Progress and prospects. Ethiop Med J. 2017:55(Suppl 1):75-80.

10. Adenowo AF, Oyinloye BE, Ogunyinka BI, Kappo AP. Review article impact of human schistosomiasis in sub-Saharan Africa. Brazilian J Infect Dis. 2015; 19:196-205.

11. World Health Organization. Preventive chemotherapy in human helminthiasis. Geneva: World Health Organization; 2006. https://apps.who. int/iris/bitstream/handle/10665/43545/9241547103_eng.pdf;. Accessed 23 July 2019.

12. Federal Democratic Republic of Ethiopia Ministry of Health. Second Edition of Ethiopia National Master Plan for neglected tropical diseases. Addis Ababa: Federal Ministry of Health Ethiopia; 2016.

13. Deribe K, Meribo K, Gebre T, Hailu A, Ali A, Abraham Aseffa A, et al. The burden of neglected tropical diseases in Ethiopia, and opportunities for integrated control and elimination. Parasites Vectors. 2012;5:240.

14. Chala B, Torben W. An epidemiological trend of urogenital Schistosomiasis in Ethiopia. Front Public Health. 2018;6:60

15. Sacko M, Magnussen $P$, Keita AD, Traoré MS, Landouré A, Doucouré $A$, et al. Impact of Schistosoma haematobium infection on urinary tract pathology, nutritional status and anaemia in school-aged children in two different endemic areas of the Niger River Basin, Mali. Acta Trop. 2011;120(Suppl 1): S142-50.

16. Mekonnen A, Legesse M, Belay M, Tadesse K, Torben W, Teklemariam Z, et al. Efficacy of Praziquantel against Schistosoma haematobium in Dulshatalo village, western Ethiopia. BMC Res Notes. 2013;6:392.

17. Abebe N, Erko B, Medhin G, Berhe N. Clinico-epidemiological study of Schistosomiasis mansoni in Waja-Timuga, District of Alamata, northern Ethiopia. Parasites Vectors. 2014;7:158.

18. Jukes MC, Nokes CA, Alcock KJ, Lambo JK, Kihamia C, Ngorosho N, et al. Heavy schistosomiasis associated with poor short-term memory and slower reaction times in Tanzanian schoolchildren. Tropical Med Int Health. 2002;7:104-17.

19. Mengitsu B, Shafi O, Kebede B, Kebede F, Worku DT, Herero M, et al. Ethiopia and its steps to mobilize resources to achieve 2020 elimination and control goals for neglected tropical diseases: spider webs joined can tie a lion. Int Health. 2016:8(Suppl 1):i34-52.

20. Uniting to combat neglected tropical diseases. Mass treatment coverage for NTDs - 2016: Ethiopia and neglected tropical diseases. https:// unitingtocombatntds.org/wp-content/uploads/2018/01/Ethiopia_eng.pdf. Accessed 10 July 2019

21. Shumbej T, Menu S, Girum T, Bekele F, Gebru T, Worku M, Alemayehu M, et al. Impact of annual preventive mass chemotherapy for soil-transmitted helminths among primary school children in an endemic area of Gurage zone: a prospective cross-sectional study. Res Rep Trop Med. 2019;10:109-18.

22. Woldegerima E, Bayih AG, Tegegne Y, Aemero M, Zeleke AJ. Prevalence and reinfection rates of Schistosoma mansoni and Praziquantel efficacy against the parasite among primary school children in Sanja town, Northwest Ethiopia. J Parasitol Res. 2019. https://doi.org/10.1155/2019/3697216.

23. Jemaneh L. Soil-transmitted Helminth infections and Schistosomiasis mansoni in school children from Chilga District, Northwest Ethiopia. Ethiop J Health Sci. 2001;11:79-87.

24. Shumbej T, Girum T. Helminth infections in light of an ongoing intervention in endemic areas of Guragae zone, southern Ethiopia: an implication for neglected tropical diseases elimination in Ethiopia by 2020. Trop Dis Travel Med Vaccines. 2019;5:8.

25. World Health Organization: Basic Laboratory Methods in Medical Parasitology. Geneva: WHO; 1991.

26. Sakti H, Nokes C, Hertanto WS, Hendratno S, Hall A, Bundy DA, et al. Evidence for an association between hookworm infection and cognitive function in Indonesian school children. Tropical Med Int Health. 1999;4(5):322-34.

27. Da Silvaa LC. Chieffi PP and Carrilhoa. Schistosomiasis mansoni - clinical features. Gastroenterol Hepatol. 2005;28:44-53.

28. Stephenson L. The impact of schistosomiasis on human nutrition. Parasitology. 1993;107:S107-23. 
29. Assis AM, Barreto ML, Prado MS, Reis MG, Parraga IM, Blanton RE. Schistosoma mansoni infection and nutritional status in schoolchildren: a randomized, double-blind trial in North-Eastern Brazil. Am J Clin Nutr. 1998;68:1247-53.

30. Deribew A, Kebede B, Tessema GA, Adama YA, Misganaw A, Gebre T, et al. Mortality and disability-adjusted life-years (DALYs) for common neglected tropical diseases in Ethiopia, 1990-2015: evidence from the global burden of disease study 2015. Ethiop Med J. 2017;55(Suppl 1):3-14.

31. Hailu T, Alemu M, Abera B, Mulu W, Yizengaw E, Genanew A, et al. Multivariate analysis of factors associated with Schistosoma mansoni and hookworm infection among primary school children in rural Bahir Dar, Northwest Ethiopia. Trop Dis Travel Med Vaccines. 2018;4:4.

32. Alebie G, Erko B, Aemero M, Petros B. Epidemiological study on Schistosoma mansoni infection in Sanja area, Amhara region, Ethiopia. Parasites Vectors. 2014;7:15

33. Ahmed H, Ahmed H, Hong S, Tag A, Bashir E, Mohamed R, et al. Prevalence , risk factors, and clinical manifestations of schistosomiasis among school children in the White Nile River basin, Sudan. Parasites Vectors. 2014;7:478

34. Steinmann P, Keiser J, Bos R, Tanner M, Utzinger J. Schistosomiasis and water resources development : systematic review, meta-analysis, and estimates of people at risk. Lancet Infect Dis. 2006;6:411-25.

35. Dejenie $T$, Petros B. irrigation practices and intestinal helminth infections in Southern and Central Zones of Tigray. Ethiop J Health Dev. 2009;23:48-56.

36. Rabone M, Wiethase JH, Allan F, Gouvras AN, Pennance T, Hamidou AA, et al. Freshwater snails of biomedical importance in the Niger River Valley evidence of temporal and spatial patterns in abundance, distribution and infection with Schistosoma spp. Parasit Vectors. 2019;12:498.

37. Dufera M, Petros B, Erko B, Berhe N, Gundersen SG. Schistosoma mansoni infection in Finchaa sugar estate: public health problem assessment based on clinical records and parasitological surveys, Western Ethiopia. Sci Technol Arts Res J. 2014;3:155-61.

38. Bruun B, Aagaard-Hansen J. The social context of schistosomiasis and its control: an introduction and annotated bibliography. Geneva: WHO; 2008.

39. Noronha CV, Barreto ML, Silva TM, Souza IM. A popular conception of Schistosoma mansoni: modes of transmission and prevention from a gender perspective. Cad Public Health , Rio de Janeiro. 1995;11:106-17.

40. Ibrahim T, Zemene E, Asres Y, Seyoum D, Tiruneh A, Gedefaw L, et al. Epidemiology of soil-transmitted helminths and Schistosoma mansoni : a base-line survey among school children, Ejaii, Ethiopia. J Infect Dev Ctries. 2018;12:1134-41.

41. Alemayehu B, Tomass Z. Schistosoma mansoni infection prevalence and associated risk factors among schoolchildren in Demba Girara, Damot Woide District of Wolaita zone, southern Ethiopia. Asian Pac J Trop Med. 2015;8:457-63.

42. Tchuente LT, Stothard JR, Rollinson D and Reinhard-Rupp J. Precision mapping : An innovative tool and way forward to shrink the map , better target interventions, and accelerate toward the elimination of schistosomiasis. PLoS Negl Trop Dis 2018; 12: e0006563. https:/doi.org/https:/doi.org/10.1371/journal.pntd.0006563.

43. Federal Democratic Republic of Ethiopia Ministry of Health. Health Sector Development Programme IV 2010/11-2014/15 Final Draft. Addis Ababa: Federal Democratic Republic of Ethiopia Ministry of Health; 2010.

44. Sokolow SH, Wood CL, Jones IJ, Swartz SJ, Lopez M, Hsieh MH, et al. Global assessment of Schistosomiasis control over the past century shows targeting the snail intermediate host works best. PLoS Negl Trop Dis. 2016; 10:e0004794. https://doi.org/10.1371/journal.pntd.0004794.

45. Massara CL, Peixoto SV, Enk MJ, Barros HDS, Carvalho ODS, Sakurai E, Schall. V. Evaluation of an improved approach using residences of Schistosomiasispositive school children to identify carriers in an area of low Endemicity. Am J Trop Med Hyg. 2006;74:495-9.

46. de Vlas SJ, Gryseets B. Underestimation of Schistosoma mansoni Prevalences. Parasitol Today. 1992;8:274-7.

47. Siqueira LMV, Coelho PMZ, de Oliveira ÁA, Massara CL, Carneiro NFF, Lima $\mathrm{ACL}$, et al. Evaluation of two coproscopic techniques for the diagnosis of schistosomiasis in a low-transmission area in the state of Minas Gerais, Brazil. Mem Inst Oswaldo Cruz, Rio de Janeiro. 2011:106:844-50.

48. Enk MJ, Lima ACL, Drummond SC, Schall VT, Coelho PMZ. The effect of the number of stool samples on the observed prevalence and the infection intensity with Schistosoma mansoni among a population in an area of low transmission. Acta Trop. 2008;108:222-8.

\section{Publisher's Note}

Springer Nature remains neutral with regard to jurisdictional claims in published maps and institutional affiliations.

Ready to submit your research? Choose BMC and benefit from:

- fast, convenient online submission

- thorough peer review by experienced researchers in your field

- rapid publication on acceptance

- support for research data, including large and complex data types

- gold Open Access which fosters wider collaboration and increased citations

- maximum visibility for your research: over $100 \mathrm{M}$ website views per year

At BMC, research is always in progress.

Learn more biomedcentral.com/submissions 